\title{
Aplicação da Técnica de Mapeamento IDEF-SIM para Identificação e Análise de Desperdícios em Uma Empresa do Setor de Construção Civil
}

Application of the IDEF-SIM Mapping Technique for Identification and Analysis of Waste in A Civil Construction Industry

\section{Resumo}

Lean pode ser definido como um conjunto de práticas para minimizar defeitos a fim de melhorar o desempenho e, assim, é uma das iniciativas que muitas das grandes empresas têm adotado a fim de se manterem competitivas nomercado. Dentre essas empresas, o setor de construção civil iniciou a sua utilização nos anos 90 e, atualmente, possui uma vertente denominada Lean na construção civil. Para uma correta aplicação do lean na construção civil é de interesse compreender quais são os principais desperdícios a serem eliminados e/ou reduzidos. Desta forma, este trabalho visa identificar e sugerir melhorias para eliminação e/ou redução dos 7 tipos de desperdícios adotados no pensamento lean na linha de produção do tubo de concreto jp dn 400 de uma empresa do setor de construção civil. Para a identificação desses desperdícios, este trabalho será conduzido de acordo com a metodologia adotada por meio das seguintes etapas: estudo da teoria, definição do caso a ser estudado, condução da pesquisa de campo, realização do mapeamento, validação do mapeamento, análise e, por fim, a conclusão. Como resultado, foi possível a identificação de cinco tipos de desperdícios e sendo estes os desperdícios do tipo transporte, processamento, movimentação, retrabalho e estoque. Vale ressaltar que a técnica idef-sim permitiu uma fácil visualização dos desperdícios do tipo movimentação e processamento.

Palavras-chave:

\section{Abstract}

Lean can be defined as a philosophy or strategy that relies on a set of practices to minimize defects with the purpose to improve the performance of a company and, thus, is one of the initiatives that many large companies around the world have tried to adopt with the purpose to remain competitive in an increasingly global market. Among these companies, the contruction industry began its use in the 90's and currently has a section called lean construction. For a correct application of lean is great to understand what are the mainwastes to be eliminated and/or reduced in construction. Thus, this study aims to identify and suggest improvements for elimination and/or reduction of the 7 types of wastes adopted in lean thinking in the production line of concrete pipe jp an 400 from a company in the construction industry. For the identification of these wastes, this study will be conducted in accordance with the methodology adopted by the following steps: study of theory, case definition to be studied, conducting field research, performing mapping, validation mapping, analysis and the conclusion. As a result it was possible to identify five types of wastes from the 7 types covered by the lean philosophy like transportation, processing, motion, defects and inventory. It is notable that the use of idef-sim technique allowed easy viewing of the waste motion and processing type.

Keywords:

\footnotetext{
1. Av. B P S, 1303, Pinheirinho, Itajubá, MG, 37500-015, tpmussolini@yahoo.com.br

2. juliana_hdg@yahoo.com.br

MUSSOLINI, T. P.; GAUDENCIO, J. H. D. Aplicação da técnica de mapeamento idef-sim para identificação e análise de desperdícios em uma empresa do setor de construção civil. GEPROS. Gestão da Produção, Operações e

Sistemas, v. 14, n.3, p. $14-28,2019$.
DOI: $10.15675 /$ gepros.v14i3.2599
} 


\section{INTRODUÇÃO}

Com os programas de melhorias contínuas as organizações buscam garantir a qualidade de seus produtos e processos para garantir que estas atinjam seus objetivos de produção com mínimo desperdício. Entretanto, ressalta-se que um produto ou processo possui mais de uma característica de qualidade e que se mais de uma for apontada como alvo, uma enorme dificuldade pode ser encontrada. Cabe aos gestores à definição de quais são as características de qualidade prioritárias em atendimento a um mercado consumidor específico.

No caso da construção civil, particularmente no Brasil, ela está em uma fase de crescimento, principalmente, em obras de saneamento básico. Dentro deste contexto, surge a proposta para o presente trabalho com o objetivo de identificar e sugerir melhorias para a eliminação ou redução dos 7 tipos de desperdícios em uma linha de produção de uma empresa do setor de construção civil, através da técnica IDEF-SIM.

Devido ao rápido crescimento por este tipo de produto, as empresas do setor veem buscando identificar possíveis melhorias com o propósito de aumentar o volume produzido, reduzindo os custos e minimizando os desperdícios (LEAL; CAMPOS, 2017). Como objeto de estudo será utilizada a linha de produção do tubo de concreto JP DN 400 por apresentar um grande volume de produção diário em uma empresa do setor de construção civil localizada na grande São Paulo conforme ilustrado na Figura 1.

Figura 1 - (a) Máquina Radial da linha de produção e (b) Tubos de concreto JP DN 400 acabados

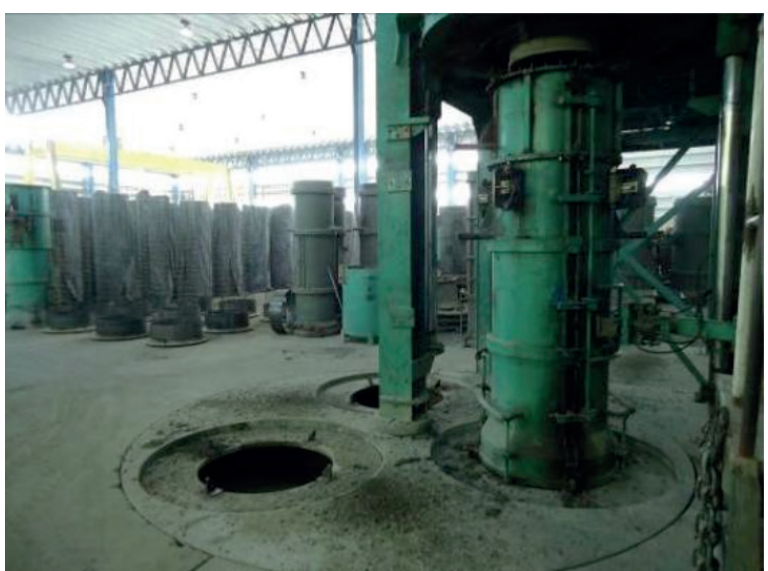

(a)

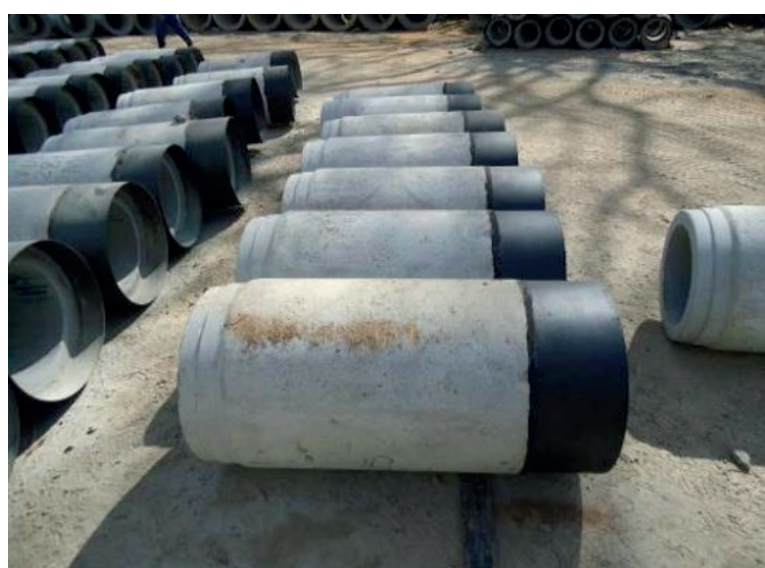

(b)

Fonte: Elaboração dos autores. 
Com isso, este trabalho focará na busca pelos 7 tipos de desperdícios abordados na filosofia Lean. Sendo eles: Superprodução; Espera; Transporte; Processamento; Movimentação; Retrabalho; e Estoque.

A busca por esses 7 tipos de desperdícios será auxiliada com a técnica de mapeamento IDEF-SIM que até o momento foi utilizada apenas para a orientação de projetos de simulação de acordo com Leal et al. (2010). O mapeamento fornecerá uma visão de todo o processo desde a entrada da matéria prima até a concepção do produto final e, com isso, possíveis desperdícios poderão ser detectados durante o mapeamento das etapas do processo.

Este trabalho não tem como propósito comparar a técnica de mapeamento IDEF-SIM com a ferramenta Mapeamento do Fluxo de Valor, do inglês Value Stream Mapping (VSM), a qual é amplamente utilizada na identificação do fluxo de materiais, informações e de atividades que agregam ou não valores nos processos produtivos voltados para a filosofia lean, mas, sim, verificar a viabilidade da utilização da técnica IDEF-SIM na identificação dos desperdícios.

\section{REVISÃO BIBLIOGRÁFICA}

\subsection{Filosofia enxuta (Lean Manufacturing)}

A filosofia enxuta é definida como uma filosofia ou estratégia que depende de um conjunto de práticas para minimizar defeitos a fim de melhorar o desempenho da empresa conforme descrito em Womack, Jones e Roos (2004) . Segundo Hosseini Nasab et al. (2012) , a filosofia enxuta, com origem no Sistema Toyota de Produção é uma das iniciativas que muitas das grandes empresas em todo o mundo têm tentado adotar, a fim de se manterem competitivas no mercado cada vez mais global. Womack, Jones e Roos (2004) usaram o termo "filosofia enxuta" para contrastar o sistema Toyota com a "produção em massa" ocidental em seu livro "A máquina que mudou o mundo" conceituando essa forma de gerenciar a produção da seguinte maneira:

- SWistema produtivo integrado, com enfoque no fluxo de produção, produção em pequenos lotes baseando-se no just-in-time (JIT) e estoques reduzidos;

- Propicia ações preventivas de defeitos ao invés de ações corretivas;

- Atua com enfoque na produção puxada ao invés da produção empurrada baseadas em previsões de demanda;

- É flexível, sendo organizada por meio de equipes de trabalho formadas por mão-de-obra que possuem várias funções ou utilidades diferentes;

- Solução das causas de problemas objetivando a maximização do valor agregado ao produto final;

- Relacionamento de parceria intensiva desde o primeiro fornecedor até o cliente final. 
Resumindo, de acordo com Hosseini Nasab et al. (2012), o foco desta abordagem multidimensional é a redução de custos por meio da eliminação de atividades que não agregam valor, e usando ferramentas como JIT, manufatura celular, manutenção produtiva total, nivelamento da produção, redução de setup e outros para omitir o desperdício e, assim, a implementação das práticas lean de produção geram melhores resultados operacionais, tais como um inventário reduzido.

No entanto, embora a implantação dos conceitos lean tenha como objetivo o aumento da competitividade das empresas, isto pode não ocorrer imediatamente, pois fatores como o tipo da empresa ou o tipo do produto podem influenciar os resultados ( LEWIS, 2000) .

\subsection{Lean na Construção Civil}

O Lean na Construção Civil, do inglês Lean Construction, foi derivado do Lean Manufacturing e concebido no início dos anos 90, tendo como marco principal a publicação do trabalho "Application of the new production philosophy in the construction industry" por Koskela (1992) . De acordo com Koskela (1992), os problemas da construção civil são bem conhecidos. A produtividade da construção civil possui defasagens quando comparadas às indústrias de fabricação, por exemplo, a segurança no trabalho é notoriamente pior do que em outras indústrias e devido às condições de trabalho ser inferior, há escassez de funcionários.

Koskela (2000) definiu que para uma correta aplicação do Lean na Construção Civil é de elevado interesse compreender quais são os principais desperdícios a serem eliminados na construção. Com isso, os 7 desperdícios identificados por Ohno (1988) e adotados no pensamento Lean serão detalhados a seguir.

1. Superprodução: produção excessiva devido à utilização de demasiados recursos;

2. Espera: falta de prontidão nos recursos originando tempo de espera;

3. Transporte: etapas desnecessárias no processo;

4. Processamento: excesso de recursos na realização de uma tarefa que não agrega valor;

5. Movimentação: deslocWamento de materiais, equipamentos e pessoas;

6. Retrabalho: defeitos na produção e, assim, originando a correção dos mesmos;

7. Estoque: elaboração de excesso de inventários de materiais.

Hirota e Formoso (2000) advertem que a aplicação dos conceitos da filosofia enxuta na construção civil deve resultar de um processo de transferência e não de réplica, entendendo transferência como um termo genérico que expressa tanto um estudo de práticas bem sucedidas quanto à aprendizagem por meio da ação durante a implementação dessas práticas. 


\subsection{Modelagem IDEF-SIM}

A técnica IDEF-SIM (Integrated Definition Methods - Simulation) possui como foco projetos de simulações, porém é compatível para outros fins, como projetos de melhoria em geral conforme detalhado em Leal et al. (2009). A Tabela 1 apresenta os elementos e a simbologia utilizada na técnica IDEF-SIM que foi publicada, pela primeira vez, no trabalho de Leal (2008), porém somente em casos hipotéticos de simulação. A técnica IDEF-SIM também foi utilizada em alguns trabalhos como Montevechi et al. (2010), Rangel e Cunha (2010) e em Rangel e Nunes (2011).

Tabela 1 - Simbologia da técnica IDEF-SIM

Elementos
Entidade
Funções
Fluxo da entidade
Recursos
Controles
Regras para fluxos paralelos
e/ou alternativos
Informação explicativa
Fluxo de entrada no sistema modelado

Fonte: Adaptado de Leal et al. (2009).

\section{METODOLOGIA DE PESQUISA}

Este capítulo apresenta o modo como esse trabalho foi conduzido de acordo com as etapas descritas no fluxograma representado pela Figura 2.

A primeira etapa realizada foi o estudo da teoria que acarretou na pesquisa demonstrada na seção 2 o qual aborda as definições da filosofia lean e, em específico, o lean na construção civil, os seus 7 tipos de desperdícios e, por fim, a definição do mapeamento realizado pela técnica IDEF-SIM. Em decorrência desse estudo, objetivos foram traçados e definiu-se que o caso a ser estudado seria a linha de produção do tubo de concreto JP DN 400 de uma fábrica do ramo de construção civil. Após a escolha, iniciou-se a condução da pesquisa de campo através de visitas à empresa. Fotos foram retiradas e o 
acompanhamento de cada uma das etapas da fabricação foi realizado em tempo real para possibilitar o entendimento do processo. Informações mais detalhadas como, por exemplo, as proporções de matérias-primas utilizadas, número de produção diária, números de operadores e seus respectivos papéis dentro do processo foram obtidos através de reuniões com a gerência.

De posse de todas as informações necessárias, deu-se início a construção do mapeamento do processo através da técnica IDEF-SIM. Após a sua conclusão, o mapeamento foi validado por meio da sua apresentação ao especialista do processo o qual o comparou e verificou que este representa fielmente a situação real e, assim, validando o mapeamento.

Em sequência, a análise do processo é iniciada com a identificação dos 7 tipos de desperdícios abordados na filosofia lean. Foi possível analisar todas as etapas desde as entradas de matérias-primas até a saída do produto final e, assim, propiciando a oportunidade de se encontrar desperdícios recorrentes na linha de produção. Caso desperdícios sejam encontrados, propõem-se sugestões de melhorias no processo de fabricação.

Por fim, a última etapa na condução desse trabalho é concluir se o mapeamento do processo de fabricação do tubo de concreto JP DN 400 realizado através da técnica IDEF-SIM foi capaz de auxiliar na análise dos 7 tipos de desperdícios.

Figura 2 - Fluxograma da metodologia de pesquisa

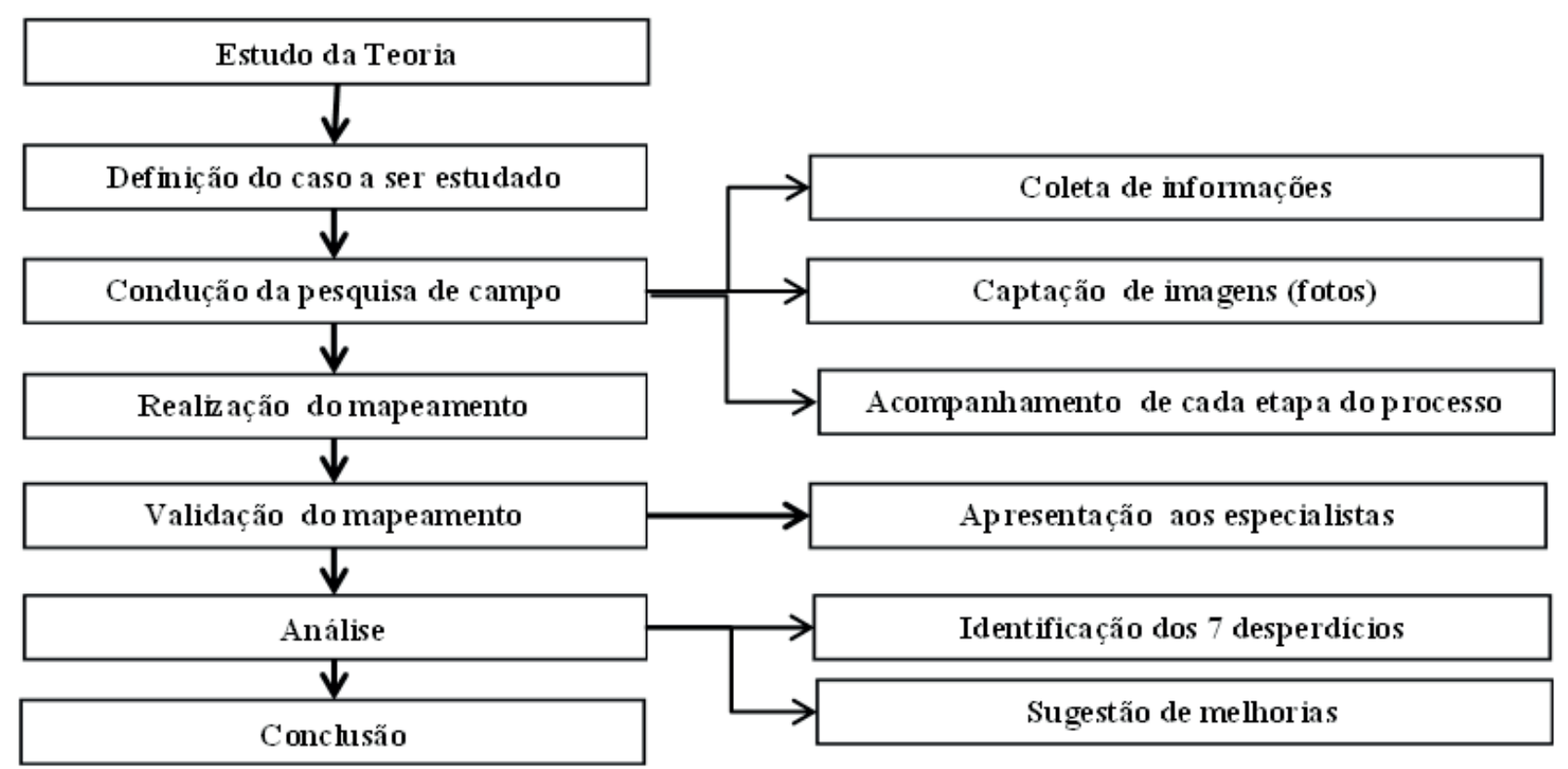

Fonte: Elaboração dos autores. 


\section{APLICAÇÃO}

Com o intuito de atingir o objetivo deste trabalho, este capítulo aborda o desenvolvimento das atividades que irão identificar e propor as melhorias para a eliminação ou redução dos 7 tipos de desperdícios em uma linha de produção de uma empresa do setor de construção civil líder do segmento de pré-moldados, especificamente, da produção de tubos de concreto JP.

\subsection{Mapeamento}

O processo em análise necessita de nove itens de matéria-prima, sendo sete para a preparação da massa de concreto e dois para a estrutura de aço que formam o produto final. Nesta seção as etapas do processo de fabricação são detalhadas conforme as Figuras 3, 4 e 7 geradas a partir do software DIA ${ }^{\circledR}$. A primeira etapa do processo, representada pela Figura 3, ilustra a preparação da massa de concreto para um ciclo de fabricação.

Figura 3 - Mapeamento da etapa de preparação de massa de concreto

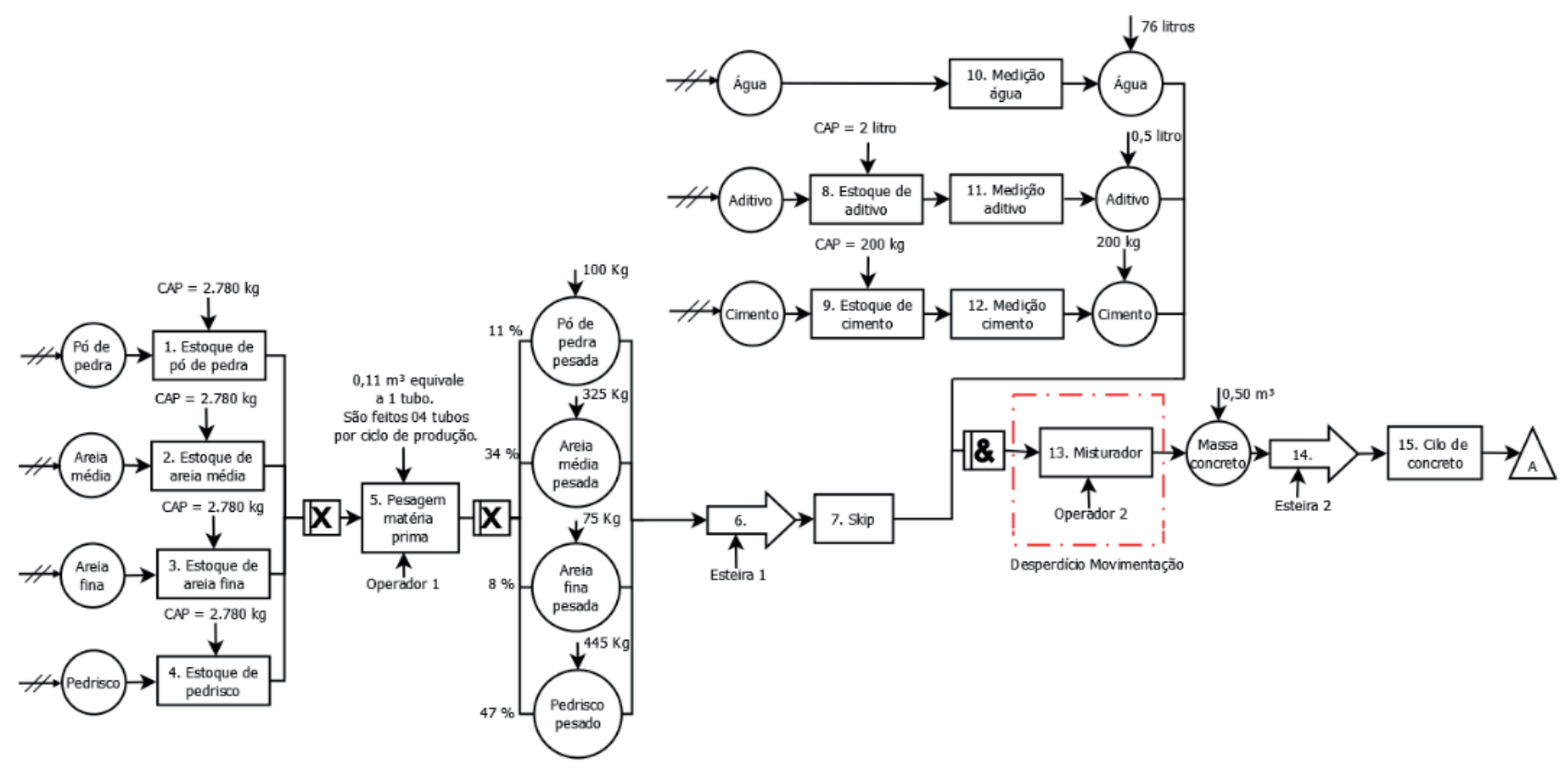

Fonte: Elaboração dos autores.

As matérias-primas pó de pedra, areia média, areia fina e pedrisco são estocadas em seus respectivos locais de acordo com a capacidade máxima que é de $2.780 \mathrm{~kg}$. Estas são pesadas individualmente em um processo automático após o comando do operador 1. Esta pesagem é realizada para 
um ciclo de produção que corresponde a 4 tubos de concreto.

Após cada operação de pesagem, as matérias-primas são transportadas pela esteira 1 (a) para o local 7 (skip) (b) que assemelha-se a um elevador e transporta as quatro matérias-primas juntas para o local 8 (misturador). Também são acrescidas no local 8 as demais matérias-primas como água, aditivo e cimento que são dimensionadas automaticamente vindas dos locais 10, 11 e 12. Após a junção de todas as matérias-primas no local 13 (misturador), o operador 2 é responsável por liberar a execução do processo de mistura que atua por aproximadamente 5 minutos e, assim, como resultado, tem-se a massa de concreto que é transportada através da esteira 2 para o local 15 (cilo de concreto).

A segunda etapa do processo, representada pela Figura 4, ilustra a fabricação da armação de aço que juntamente com a massa de concreto representada no mapeamento da Figura 3 irão compor o tubo de concreto. Essa etapa é representada para a fabricação de uma armação que caracteriza a demanda de um tubo de concreto. Para a realização dessa etapa, são necessários quatro operadores $(3,4,5$ e 6$)$ os quais estão aptos a realizarem quaisquer umas das funções dos locais 16, 17, 18, 19 e 20. Como primeira matéria-prima, o rolo de chapa de aço é transportado para o local 16 (marcação) onde é desenrolado no chão da fábrica para que o processo de marcação seja realizado. Em sequência, dois operadores trabalham na etapa de corte no local 17 em que um realiza o corte com uma esmerilhadeira e o outro agrupa as chapas já cortadas em um carrinho de transporte que será encaminhado para o próximo local conforme a Figura 5.

Figura 4 - Mapeamento da etapa de fabricação da armação de aço

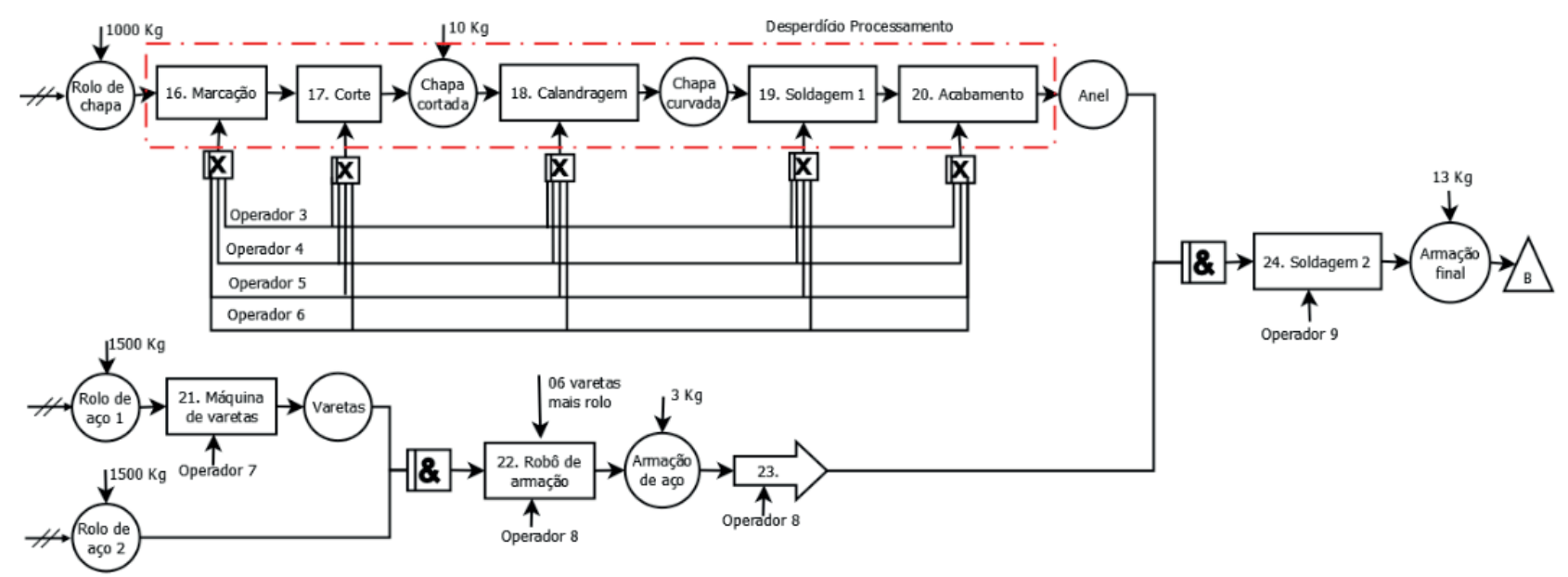

Fonte: Elaboração dos autores. 
Figura 5 - Processo de marcação (a) e processo de corte (b) do rolo de chapa de aço
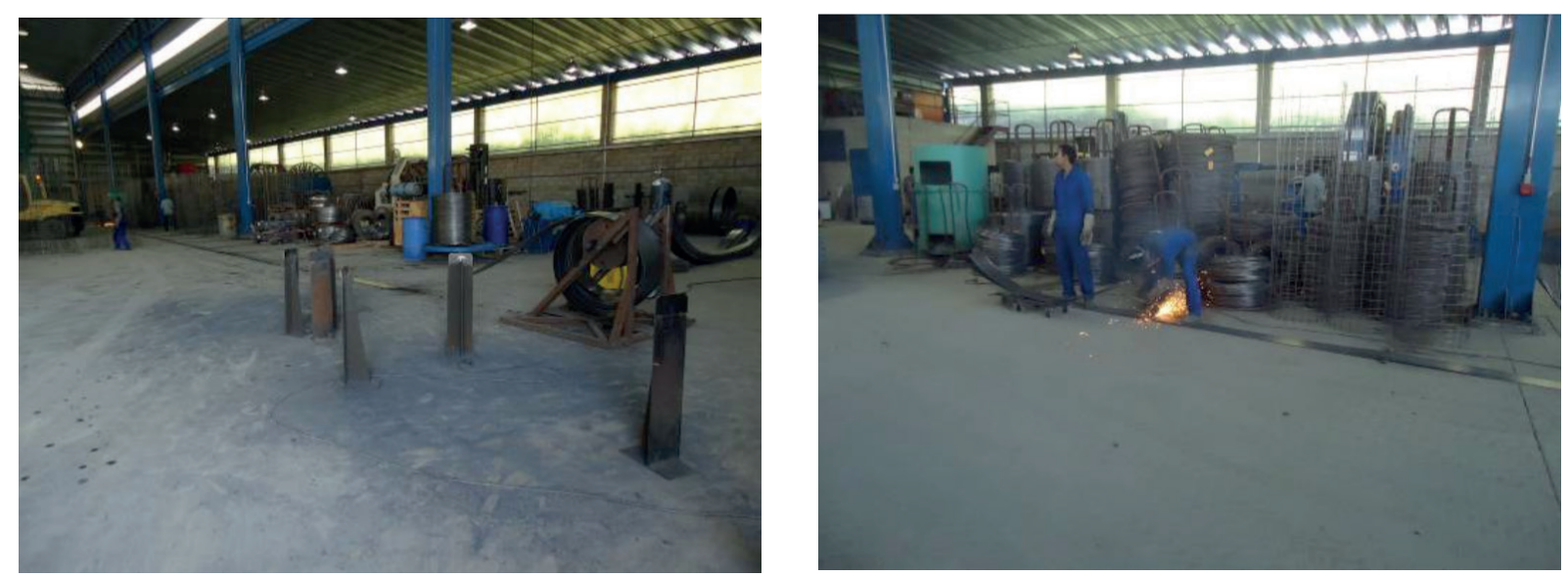

Fonte: Elaboração dos autores.

No local 18, a etapa de calandragem é realizada por um operador com o auxílio de máquina (Figura 6) que transforma a chapa em uma chapa de aço curvada. Após, a chapa curvada é transportada para o local 19 aonde outro operador realiza a solda nas pontas das chapas e, finalmente, a chapa soldada é transportada para o local 20 onde o processo de acabamento é realizado e, assim, obtendo-se o anel.

Figura 6 - Máquina Calandra (a) e as chapas de aço curvadas (b) originadas do processo de calandragem
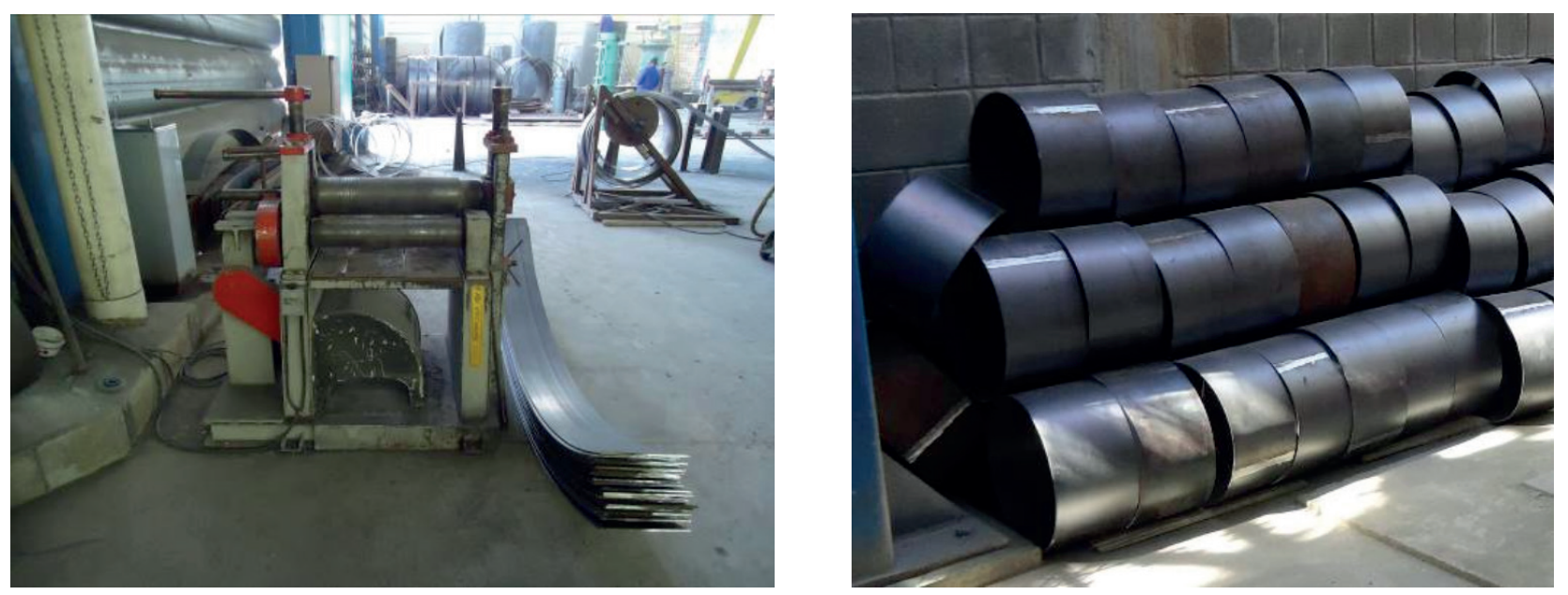

Fonte: Elaboração dos autores.

Em paralelo a fabricação do anel, a armação de aço é fabricada com dois rolos de aço como matérias-primas. Do primeiro rolo de aço utiliza-se uma porcentagem para a fabricação de seis varetas por uma máquina com o auxílio do operador 7, no local 21. Já do segundo rolo de aço utiliza-se outra proporção que juntamente com as varetas constituem o processo de formação da estrutura da armação de aço, realizado por um robô semiautomático, com o auxílio do operador 8, no local 22. Após a conclusão da armação, esse operador realiza o transporte da mesma para o local 24 onde a 
etapa de soldagem da estrutura da armação com o anel é realizada pelo operador 9 e, assim, obtendo-se a armação final.

A terceira e a quarta etapas do processo, representadas pela Figura 7, demonstram o processo final da produção do tubo e, em sequência, o seu processo de inspeção e ensaios.

Figura 7 - Mapeamento do processo final de fabricação do tubo de concreto e inspeção
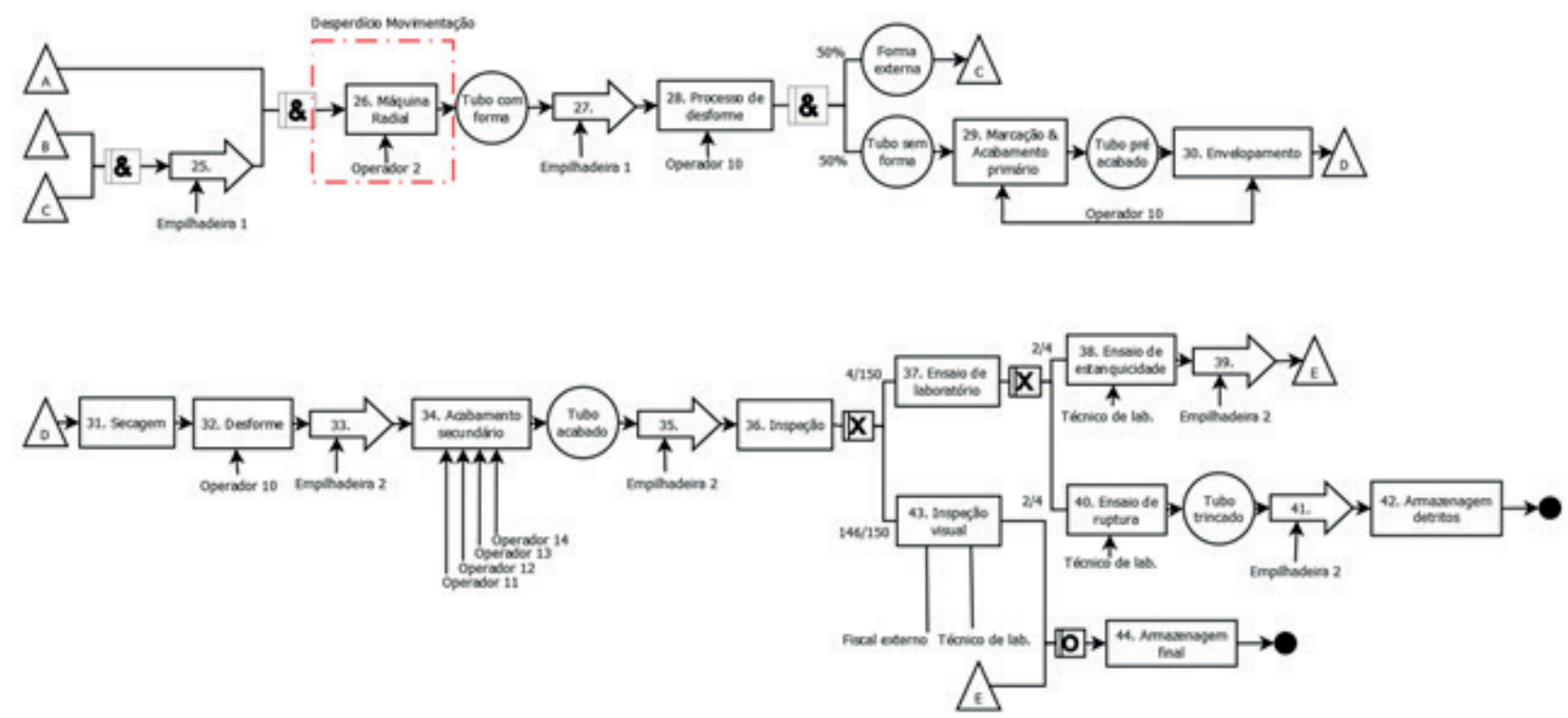

Fonte: Elaboração dos autores.

Com os processos de preparação da massa de concreto (A) e da fabricação da armação (B) finalizados, inicia-se o processo de enchimento da forma externa. Para esta etapa são necessários: (1) a massa de concreto que está armazenada no local 15 (cilo de concreto), (2) a armação final obtida pela segunda etapa e (3) a forma externa do tubo. A armação de aço é encaixada na forma externa através da empilhadeira 1 que transporta o conjunto para o local 26 (Máquina Radial) aonde inicia-se o processo de enchimento com o auxílio do operador 2.

O processo de enchimento da máquina Radial leva em torno de 4 minutos e, após, o tubo com forma é transportado pela empilhadeira 1 para o local $28 \mathrm{em}$ que a forma externa é retirada do tubo de concreto com o auxílio do operador 10. Como saídas desse processo têm-se a forma externa que é reaproveitada para o próximo tubo e o tubo de concreto sem acabamento que é transportado para o local 29 onde o operador 10 realiza as funções de marcação seguindo a norma brasileira ABNT NBR 15319. Assim, originando o tubo pré-acabado que é levado ao local 30 onde, ainda o operador 10, realiza o envelopamento para que o mesmo fique na etapa de secagem no local 31.

Após a secagem, o operador 10 retira a capa plástica, no local 32 (desforme), utilizada para o processo de secagem. Em sequência, a empilhadeira 2 transporta o tubo para o local 34 onde acon- 
tecerá a etapa do acabamento secundário e, sendo que, neste processo, quatro operadores trabalham em diversas funções.

Com o término do acabamento secundário, inicia-se a quarta etapa em que se realizam inspeções e ensaios no tubo para verificar a sua qualidade de acordo com as exigências da norma brasileira ABNT NBR 15319. A empilhadeira 2 transporta o tubo acabado para o local 36 onde será realizado o processo de inspeção no qual o mesmo poderá ser encaminhado ou para o ensaio de laboratório ou para a inspeção visual.

Dos tubos que seguem para o local 37 (ensaio de laboratório), uma proporção é encaminhada para o ensaio de estanqueidade aonde são totalmente cheios com água e suas pontas são fechadas com o objetivo de verificar a existência de vazamentos e, após o ensaio, os tubos são enviados para a armazenagem final. Os outros tubos são encaminhados para o ensaio de ruptura, no local 40, onde é testado a sua resistência e, em consequência desse ensaio, os tubos sofrem fissuras que não podem ser corrigidas e, desta forma, são desprezados em sua totalidade com o auxílio da empilhadeira 2 que os transporta para o local 42.

Por fim, os tubos que seguem para o local 43 (inspeção visual) são vistoriados pelo técnico de qualidade da empresa juntamente com um fiscal externo que, normalmente, são aprovados em sua totalidade. Após essa vistoria, os tubos são encaminhados para a armazenagem final no local 44.

\subsection{Identificação dos desperdícios}

Dentre os 7 tipos de desperdícios que este trabalho busca identificar na fabricação dos tubos de concreto, foram identificados 5 tipos os quais serão apresentados a seguir.

O primeiro desperdício encontrado foi o do tipo transporte. Devido a um layout mal dimensionado e uma armazenagem incorreta de matérias-primas utilizadas para a produção do tubo. As empilhadeiras não possuem uma padronização da movimentação e, assim, gerando um deslocamento desnecessário dentro da fábrica.

O segundo desperdício encontrado foi o do tipo processamento. Esse tipo de desperdício é claramente identificado na etapa de fabricação dos anéis de aço conforme demonstrado pelo contorno tracejado no mapeamento da Figura 5 aonde existem muitas operações para a fabricação de uma única peça (o anel) e, assim, gerando um alto custo de fabricação.

O terceiro desperdício encontrado foi o do tipo movimentação. Esse desperdício é visualmente identificado através do mapeamento apresentado pelo contorno tracejado nas Figuras 3 e 7 no qual o operador 2 tem que se deslocar entre os locais 13 (misturador) e 26 (máquina radial) para iniciar ambos os processos. As centrais de comando dessas duas máquinas estão localizados em locais diferentes e distantes entre si. Essa movimentação é realizada, aproximadamente, 35 vezes ao dia para a produção do tubo de concreto JP DN 400. 


\section{XXV}

O quarto desperdício encontrado foi o do tipo retrabalho. O acabamento secundário do tubo de concreto realizado no local 34, da Figura 7, é considerado pela empresa como sendo um acabamento final do tubo já pronto. Porém, alguns trabalhos realizados pelos operadores como a identificação de furos no tubo e seus respectivos preenchimentos e, posteriormente, o lixamento dessas correções podem ser considerados como um retrabalho do processo de fabricação uma vez que os tubos podem ser produzidos sem a presença desses furos.

O quinto e último desperdício encontrado foi o do tipo estoque. A linha de produção da armação de aço final representada pelo mapeamento da Figura 4 é realizada com, pelo menos, um dia útil de antecedência devido aos altos tempos de setup de cada operação já que essas etapas são, em sua quase totalidade, manuais. Desta forma, o gerente tomou a decisão de que a produção de armação de aço seja realizada com este período de antecedência para evitar o atraso, mas, em consequência, essa decisão acarretou em um estoque intermediário.

Por fim, os desperdícios do tipo superprodução e espera, neste trabalho, não foram identificados. O desperdício do tipo superprodução não foi identificado, pois a empresa segue o modo de produção puxada e o desperdício do tipo espera não foi identificado já que os fluxos de trabalho estão sincronizados e, assim, não existindo a presença de tempos ociosos para os operadores.

\subsection{Propostas de melhorias}

Com a identificação dos desperdícios, sugestões de melhorias na linha de produção do tubo de concreto JP DN 400 são propostas com o intuito de eliminar e/ou reduzir os cinco desperdícios identificados e abordados na filosofia lean.

A primeira sugestão é em decorrência do desperdício do tipo transporte em que um layout mal dimensionado acarreta em um excesso de movimentação das empilhadeiras. A sugestão é a implantação da metodologia $5 \mathrm{~S}$ também abordada na filosofia lean que tem como objetivo organização e disciplina no local de trabalho. Desta forma, com a implantação da metodologia 5S, o layout do estoque de materiais seria mais bem dimensionado, liberando espaço físico na fábrica e, assim, melhorando o fluxo de movimentação das empilhadeiras.

A segunda sugestão de melhoria é em decorrência do desperdício do tipo processamento que existe na etapa de fabricação dos anéis de aço. A sugestão é a realização de um estudo de viabilidade econômica para que se possa mensurar a viabilidade ou não de se manter essa produção internamente na fábrica, já que é um trabalho que exige um grande número de funcionários em relação aos outros processos e, assim, gerando um alto custo de fabricação para uma única peça que é o anel de aço.

A terceira sugestão de melhoria é em decorrência do desperdício do tipo movimentação. A 
sugestão de melhoria é a centralização dos painéis de comando que o operador aciona tanto para iniciar o funcionando da máquina Radial quanto para iniciar o funcionamento do misturador. O ideal é que o painel de comando que aciona o misturador fosse acoplado ao painel de comando que aciona a máquina Radial.

A quarta sugestão de melhoria é em decorrência do desperdício do tipo retrabalho que ocorre na identificação e preenchimento de furos no tubo de concreto já pronto. A sugestão é a aplicação da metodologia seis sigma que é um conjunto de práticas que visam melhorar sistematicamente os processos ao eliminar os seus defeitos e, assim, a ideia geral da abordagem é fazer um controle sistemático da produção para que o produto seja fabricado sem os furos uma vez que esse número pode variar.

Por fim, a quinta sugestão de melhoria é em decorrência do desperdício do tipo estoque que ocorre na linha de produção da armação de aço final. A sugestão de melhoria seria a realização de um estudo através da cronoanálise para identificar o tempo ideal de antecedência para a fabricação da armação de aço. Também, é sugerida a implantação da metodologia de Manutenção Produtiva Total, do inglês Total Productive Maintenance (TPM) que auxiliará na realização de um programa de agendamento de manutenções preventivas com o intuito de diminuir a possibilidade de quebra ou parada do robô de armação.

\section{CONCLUSÃO}

Neste trabalho foi proposto um estudo da utilização da técnica de mapeamento IDEF-SIM para a identificação dos 7 tipos de desperdícios abordados na filosofia lean. O mapeamento foi realizado em um trabalho conjunto com a gerência da fábrica e, assim, foi possível a identificação de cinco tipos de desperdícios dentre os 7 tipos abordados pela filosofia lean. Os cinco desperdícios encontrados foram: transporte, processamento, movimentação, retrabalho e estoque. Os desperdícios do tipo superprodução e espera não foram identificados.

De posse dos cinco tipos de desperdícios identificados na linha de produção, sugestões de melhorias foram propostas. As soluções apresentadas foram baseadas em técnicas apropriadas dentro dos diversos conceitos da melhoria da qualidade e, ao menos, uma sugestão para cada tipo de desperdício foi sugerida para a empresa.

Por fim, a utilização da técnica de mapeamento IDEF-SIM como ferramenta de auxílio na identificação dos desperdícios foi investigada. Como resultado foi possível verificar que o uso da técnica para a identificação dos desperdícios do tipo movimentação e processamento é aplicável devido a fácil visualização. Já para os outros três tipos de desperdícios encontrados, não foi possível uma nítida visualização por meio do mapeamento os quais foram identificados pela observação direta 
no processo. Assim, conclui-se que, neste trabalho, a técnica de mapeamento IDEF-SIM foi útil na identificação de dois desperdícios. Entretanto, esse resultado não descarta o uso da técnica em outros processos produtivos.

\section{Referências}

HIROTA, E. H.; FORMOSO, C. T. O processo de aprendizagem na transferência dos conceitos e princípios da produção enxuta para a construção. In: EXCELENTE ENCONTRO NA ÁREA DE TECNOLOGIA DO AMBIENTE CONSTRUÍDO. 8. 2000. Anais... ENTAC. p.572-579, Salvador, BA, 2000.

HOSSEINI, N. H.; ALIHEIDARI, B. T.; KHADEMI, Z. H. Finding a probabilistic approach to analyze lean manufacturing. Journal of Cleaner Production, v. 29-30, p. 73-81, 2012.

KOSKELA, L. Application of the new production philosophy to construction. Technical Report, $\mathbf{n}$. $72,1992$.

KOSKELA, L. An exploration towards a production theory and its application to construction. Technical Research Centre of Finland, VTT Publications, p. 296 - 408, 2000.

LEAL, F. Análise do efeito interativo de falhas em processos de manufatura através de projeto de experimentos simulados. Tese. 237f. 2008. (Doutorado em Engenharia Mecânica) - Universidade Estadual Paulista, Faculdade de Engenharia de Guaratinguetá, 2008.

LEAL, F.; MOURA, M. L.; ALVES, D.; MONTEVECHI, A. B. Desenvolvimento e aplicação conceitual de processos em projetos de simulação : o IDEF-SIM. In: ENCONTRO NACIONAL DE ENGENHARIA DE PRODUÇÃO. 29. 2009. Anais...ENEGEP, Salvador, BA, 2009.

LEAL, D. A.; CAMPOS, V. R. Análise da relação entre os princípios de movimentação e armazenamento e os princípios lean. In: XXIV SIMPÓSIO DE ENGENHARIA DE PRODUÇÃO. 24. 2017. Anais...SIMPEP, Bauru, SP, 2017.

LEWIS, M. A. Lean production and sustainable competitive advantage. International Journal of Operations \& Production Management, v. 20, n. 8, p. 959-978, 2000.

MONTEVECHI, J. A. B.; LEAL, F.; PINHO, A. F. DE; COSTA, R. F. DA S.; OLIVEIRA, M. L. M. DE. Conceptual modeling in simulation projects by mean adapted IDEF: an application in a brazilian tech company. In: WINTER SIMULATION CONFERENCE. 2010. Anais... MD: IEEE, p.1624-1635, Baltimore, 2010.

OHNO, T. Toyota production system. Tokyo, Japan: Diamond, Inc., 1988.

RANGEL, J. J. DE A.; CUNHA, A. P. A simulation model to evaluate sugarcane supply systems. In: WINTER SIMULATION CONFERENCE. 2010. Anais... IEEE (Ed.), p.2114-2125, Baltimore, MD, 2010. 
RANGEL, J. J. DE A.; NUNES, A. F. Use of IDEF-SIM to document simulation models. In: WINTER SIMULATION CONFERENCE. Anais... AZ: IEEE, p.1542-1553. Phoenix, 2011.

WOMACK, J. P.; JONES, D. T. A mentalidade enxuta nas empresas: elimine o desperdício e crie riqueza. Rio de Janeiro, Editora Campus, 2004.W

WOMACK, J. P.; JONES, D. T.; ROOS, D. A máquina que mudou o mundo. Rio de Janeiro, Editora Campus, 2004. 